\title{
COMO CONHECER O TRABALHO QUANDO O TRABALHO NÃO É MAIS O TRABALHO?
}

\author{
HOW TO RECOGNIZE WORK WHEN IS NOT WORK ANYMORE?
}

\author{
Abdallah Nouroudine ${ }^{1}$
}

Resumo Como conhecer o trabalho quando o trabalho não é mais o trabalho? Esta pergunta comporta dois aspectos: o primeiro é de ordem metodológica (como conhecer o trabalho?). O segundo diz respeito a este objeto hipotético que seria 'o trabalho que não é mais o trabalho'. Se este último designa o trabalho não mercantil e o trabalho informal por distinção (ou oposição) ao trabalho mercantil, então o 'trabalho que não é mais o trabalho' continua sendo, na realidade, um trabalho. Todavia, ele é diferente do trabalho mercantil, que, de acordo com uma postura etnocêntrica, supostamente constitui uma referência para a avaliação da natureza das atividades humanas. Mas, qualquer que seja o modo de trabalho dominante num coletivo de vida, uma análise da norma na atividade dita informal, do duplo ponto de vista do conceito e da experiência, permite sugerir que uma atividade humana socializada não pode ser verdadeiramente informal. Algumas balizas metodológicas permitem tentar compreender as atividades supostamente informais, chamando a atenção para os princípios epistemológicos da ergonomia e da ergologia.

Palavras-chave trabalho informal; trabalho não mercantil; trabalho mercantil; norma; dispositivo dinâmico a três polos.
Abstract How to recognize work when is not work anymore? This question entails two aspects: the first one is a question of method (how to recognize work?). The second one is about this hypothetical subject that is 'work when it is not work anymore?'. If we talk about non-profit and informal work opposed to 'standard' work, then 'work that is not work anymore' is actually still work. Although, from an ethnocentric point of view, it is different from 'standard' work, which is supposed to be a reference in order to identify the nature of human activities. However, when analyzing the norm in informal activities, whatever the prevailing kind of work in a society, and from a conceptual as well as from a practical point of view, allows us to consider that a social human activity cannot be informal. A few methodological points will help us to understand these activities supposed to be informal, focusing on ergonomic's and ergology's epistemic principles.

Keywords informal work; non-profit work; formal work; norm; dynamic three poles system. 
Como conhecer o trabalho quando o trabalho não é mais o trabalho? Esta pergunta comporta dois aspectos: o primeiro é de ordem metodológica (como conhecer o trabalho?). O segundo diz respeito a este objeto hipotético que seria 'o trabalho que não é mais o trabalho'. Antes de propor pistas de reflexão sobre o primeiro aspecto do tema, tentaremos, inicialmente, esclarecer o que está em questão na expressão 'o trabalho que não é mais o trabalho', analisando particularmente as relações entre, de um lado, o trabalho mercantil e, de outro, o trabalho não mercantil e o 'trabalho informal'. Isso nos levará, em seguida, a examinar se uma atividade humana socializada pode ser realmente informal estudando sucintamente a questão da norma na atividade humana. Dessa forma, poderemos, finalmente, propor algumas balizas metodológicas para tentar compreender atividades supostamente informais, chamando a atenção para os princípios epistemológicos da ergonomia e da ergologia.

\section{O que é 'o trabalho que não é mais o trabalho'?}

Só se pode tentar compreender a ideia de um trabalho que não seria mais o trabalho colocando-o em relação com um trabalho que ainda seria trabalho. $\mathrm{O}$ 'trabalho que não é mais o trabalho' seria (para usar a linguagem platônica) uma aparência de trabalho em relação ao verdadeiro trabalho, ou ao trabalho 'real'. Se o verdadeiro trabalho é o trabalho mercantil (modelo do trabalho), então se pode supor que 'o trabalho que não é mais o trabalho' seria o trabalho não mercantil e o 'trabalho informal' (cópias imperfeitas do modelo). É, portanto, o caso de se determinar se o trabalho não mercantil e o 'trabalho informal' existem e funcionam efetivamente como cópias de um modelo que seria o trabalho mercantil.

\section{O trabalho mercantil é considerado como uma referência}

Ao fazermos alusão a um 'trabalho que não é mais realmente trabalho', estamos pensando no trabalho tal como ele se apresenta fora da norma admitida para se considerar que uma atividade humana é um trabalho. No contexto internacional atual, caracterizado pela globalização da economia e do comércio, a norma dominante do trabalho é a do trabalho mercantil, ou ainda a do "trabalho stricto sensu", tal como definido por Yves Schwartz (2000, p. 678), ou seja, "um fornecimento remunerado de bem ou serviço em uma sociedade mercantil e de direito". O desenvolvimento das atividades produtivas conheceu tamanho impulso nas sociedades ocidentais que o trabalho mercantil passou a se constituir em determinante de pertencimento social. A importância do trabalho mercantil é tamanha que, na linguagem 
corrente, os termos trabalho e trabalho mercantil se impuseram como sinônimos. Sahlins já observava a centralidade do trabalho mercantil nas sociedades ocidentais quando afirmava que:

Na cultura ocidental, a economia é o principal lugar da produção simbólica. Para nós, a produção de mercadoria é ao mesmo tempo o modo privilegiado de produção e de transmissão simbólica. O caráter único da sociedade burguesa consiste não no fato de que o sistema econômico escapa à determinação simbólica, mas naquele de que o sistema econômico é estruturalmente determinante (Sahlins, 1980, p. 262).

É porque o trabalho mercantil é "estruturalmente determinante" nas sociedades ocidentais, que ele constitui uma norma de referência em relação à qual se avalia a integração ou exclusão social e que se efetua a discriminação entre o formal e o informal nas atividades humanas. De fato, se considerarmos que o trabalho mercantil é efetivamente uma norma, sabendo que "uma norma, uma regra, é aquilo que serve para fazer bem feito, para instituir, para reinstituir" (Canguilhem, 1991, p. 179), então 'o trabalho que não é mais o trabalho' é o trabalho que apresenta um distanciamento ou uma distorção em relação a essa referência. O 'trabalho que não é mais o trabalho', por seu distanciamento em relação à norma que o trabalho mercantil constitui, seria, então, o trabalho não mercantil (muito corrente nas sociedades africanas) e o 'trabalho informal' (muito disseminado nos países do Terceiro Mundo).

\section{O 'trabalho que não é mais o trabalho' seria o trabalho não mercantil}

Na maioria das sociedades africanas, o trabalho não mercantil é um modo de trabalho socialmente valorizado e reconhecido. Ele permite adquirir bens e serviços úteis para a satisfação das necessidades vitais. E constitui um quadro no qual se efetua a troca no sentido definido por Marcel Mauss, a saber, um processo composto por três exigências: dar, receber e devolver. Mas, neste caso, o que trocamos

(...) não são exclusivamente bens e riquezas, móveis e imóveis, coisas economicamente úteis. São, antes de tudo, gentilezas, banquetes, ritos, serviços militares, mulheres, crianças, danças, festas, feiras em que o comércio é apenas um dos momentos e onde a circulação das riquezas é apenas um dos termos de um contrato muito mais geral e muito mais permanente (Mauss, 1997, p. 151).

O trabalho não mercantil baseia-se em uma troca cuja significação não é estritamente econômica. Mas, na ideia de um trabalho não mercantil, o que 
está ausente não é a característica do econômico, mas a do mercantil. Em outras palavras, porque os bens são produzidos e circulam na rede social, o trabalho não mercantil continua sendo uma atividade econômica, mas, porque os bens produzidos não são trocados como mercadorias, as atividades realizadas para produzi-las e trocá-las não são mercantis.

No trabalho não mercantil, os bens trocados são vetor um de construção e de instauração de relações sociais que podem ser pacíficas ou conflituosas. Além disso, essa troca não diz respeito apenas às coisas, mas também aos valores simbólicos derivados dos bens trocados (honras, prestígios, autoridade etc.). Não é raro que o valor simbólico derivado dos bens se sobreponha ao valor das coisas como tal. Em Comores, ${ }^{2}$ a realização do trabalho não mercantil responde a uma lógica dessa ordem. Lá, o trabalho não mercantil se apresenta como um recurso no esforço social de resolver, pelo menos em parte, problemas concretos de alimentação, de educação, de força de trabalho etc. É um vetor de reconhecimento e de integração social muito mais poderoso do que o trabalho mercantil, pois está enraizado na cultura e na história.

\section{O 'trabalho que não é mais o trabalho' seria o'trabalho informal'}

O 'trabalho informal' se distingue parcialmente do trabalho mercantil no plano dos objetivos. A lógica econômica do 'trabalho informal' é orientada para os objetivos do ganho e da solidariedade familiar, ao passo que a do trabalho mercantil está centrada no objetivo do ganho. No entanto, no 'trabalho informal' o objetivo do ganho está subordinado à exigência da solidariedade familiar. Ainda que a experiência dos países do Terceiro Mundo revele que o 'trabalho informal' permite apenas adquirir um ganho financeiro insuficiente e realizar uma modesta solidariedade familiar, esta última constitui um ponto de demarcação importante entre o 'trabalho informal' e o trabalho mercantil. Em sua análise da economia informal, Bruno Lautier revela que:

a lógica de reprodução familiar (...) prevalece sobre a lógica de crescimento da empresa, ou mesmo de maximização do lucro. Essa lógica de reprodução familiar vale igualmente em diversos casos para a família ampliada, ou mesmo para os conjuntos mais vastos como a casta africana (Lautier, 1994, p. 69).

O autor ilustra essa reflexão com o exemplo dos ferreiros na África:

Alain Morice 3 interpreta a endogamia da casta dos ferreiros em Kaolack, acoplada à contratação exclusiva das crianças de outra casta que não a do chefe da oficina, como uma manifestação da prioridade da reprodução do grupo social sobre outros objetivos. Mesmo que se possa mostrar que isso afeta desfavoravelmente a produ- 
tividade, ou coloca os ferreiros em posição de desvantagem diante de seus clientes ou fornecedores, não se pode ver em tal prioridade uma irracionalidade. O caráter 'subóptimo', do ponto de vista econômico, das relações sociais que são preservadas é, de certa maneira, o preço a pagar para que o grupo social se reproduza como grupo, e é essa lógica coletiva de reprodução que prevalece (Lautier, 1994, p. 69).

A importância do objetivo de solidariedade familiar leva a um recentramento do objetivo do lucro no 'trabalho informal' que convém não subestimar.

A inflexão do objetivo do lucro no 'trabalho informal' poderia ser, nos contextos específicos dos países do Terceiro Mundo (notadamente na África), a expressão de uma negociação difícil entre, de um lado, a pressão do modelo econômico dominante (o capitalismo) no plano mundial e, de outro, a referência ao modelo local inscrito na história baseado no trabalho não mercantil. Isto é um revelador da capacidade de infração positiva dos povos do Terceiro Mundo diante do capitalismo e da lógica da economia de mercado autorregulador que lhe é consubstancial. É ainda uma tentativa de renormalização que desloca parcialmente o trabalho do âmbito de uma economia de mercado supostamente autorreguladora para o de uma economia de mercado regulada, em que o ganho está subordinado à solidariedade familiar. Uma das particularidades notórias da regulação da 'economia informal' nas sociedades do Terceiro Mundo, em relação à regulação da economia nas sociedades ocidentais, está no fato de que ela é efetuada não pelo Estado (frequentemente enfraquecido), mas pelas unidades de produção, que muitas vezes coincidem, em sua composição, com as unidades familiares.

\section{Uma atividade humana socializada pode ser informal?}

A informalidade é, cada vez mais, atribuída a atividades importantes da vida social em sociedades em que o trabalho mercantil nem sempre constitui o meio exclusivo ou dominante para satisfazer às necessidades vitais. Por mais contestável que seja a ideia de uma 'atividade humana socializada e informal', observa-se, na literatura dos especialistas e dos organismos que intervêm nas questões do desenvolvimento, uma proliferação dos setores aos quais se atribui informalidade. Desse ponto em diante, a informalidade vai muito além do trabalho. Ora, há uma contradição teórica e prática na ideia de 'atividade humana socializada e informal' que convém demonstrar.

\section{A atribuição da informalidade vai muito além do trabalho}

Para aqueles que poderiam estar tentados a considerar que a expressão 'o trabalho que não é mais o trabalho' é despropositada e que qualquer 
controvérsia a esse respeito não passaria de uma polêmica estéril, convém precisar que, infelizmente, essa fórmula, por mais contestável que seja, não é desprovida de consequência teórica e prática. Essa expressão nada mais é, na verdade, do que uma versão, entre tantas outras possíveis, da informalidade que se atribui, em uma postura etnocêntrica, às atividades que se apresentam diferentemente em relação àquilo que nossa experiência nos leva a colocar como norma de referência. Assim, além da expressão 'trabalho informal' para designar um 'trabalho' que apresenta um distanciamento em relação ao trabalho mercantil considerado como norma, fala-se em 'aprendizagem informal' para designar um dispositivo de aprendizagem que não corresponde à aprendizagem escolar que supostamente constituiria a norma. Utiliza-se também a expressão 'economia informal' para evocar uma economia que está deslocada em relação às regras da economia liberal etc. Ora, cada uma dessas expressões remete a um setor de atividade importante da vida social: o trabalho, a educação, a economia. Bastaria levar até o limite o raciocínio que conduz a qualificar como informal cada uma dessas áreas de atividade para que se impusesse a conclusão de que existiriam sociedades humanas informais cujas atividades teriam a particularidade de ser informais. O rebaixamento ideológico e etnocêntrico de tal forma de caracterizar as atividades, os valores e as normas dos outros, do ponto de vista das relações sociais e das relações interculturais, é incontestável.

\section{Há uma contradição teórica na ideia de 'atividade humana socializada e informal'}

Mas, se é verdade que aquilo que se qualifica como informal no trabalho, na aprendizagem e na economia é a atividade realizada, então a questão que realmente importa colocar, em um primeiro momento, é saber se uma atividade socializada pode ser 'informal'. O que seria uma atividade informal? Seria uma atividade privada de forma. Ora, a privação da 'forma' poderia ser decorrência da falta de uma essência, de uma norma ou de uma estrutura na atividade em questão etc. Se a forma exprime a essência, então a 'atividade informal' seria uma atividade privada da característica essencial que faz com que uma atividade seja uma atividade. Nesse caso, é um nonsense falar em 'atividade informal'. Se se trata de uma atividade, então ela não pode ser informal; se o que está em pauta é efetivamente informal, então o que se tem em vista não é uma atividade. Se a forma designa a norma, logo a 'atividade informal' seria realizada em um deserto de normas. Mas, nesse caso, a 'atividade informal' considerada não seria aquilo que unanimemente se aceita que ela seja, a saber, uma atividade socializada, pois uma de suas características fundamentais reside na obra dialética da norma. Se a forma é a organização ou a estrutura, então a 'atividade informal' seria realizada na desordem, 
posto que desprovida de organização e de estrutura. Mas, nessa hipótese, a 'atividade informal' não teria a eficácia social que lhe permite durar e ser inscrita em um feixe de relações sociais que a valida como elemento da cultura.

Parece, portanto, que se deve concluir que, se o que chamamos de 'atividade informal' existe como atividade humana cuja realização responde a objetivos determinados, estando inscrita na dinâmica de socialização própria a determinado coletivo de vida, então a atividade em questão pode ser, eventualmente, tudo menos 'informal'.

\section{A contradição prática na ideia de 'atividade humana socializada e informal'}

Em uma abordagem mais concreta, inscrevendo aquilo que seriam as 'atividades humanas socializadas e informais' no contexto real dos coletivos de vida em questão, percebemos que a ideia de uma 'atividade informal' está em contradição com as manifestações concretas dessas atividades. O mesmo acontece com 'trabalho informal', 'aprendizagem informal' e 'economia informal'.

\section{A atividade de pesca como 'trabalho informal'}

A pesca em Comores é uma dessas atividades consideradas como pertencentes ao 'trabalho informal'. No entanto, quando analisamos a atividade de trabalho dos pescadores, muito rapidamente nos damos conta de que seu trabalho está longe de ser desprovido de normas, valores e organização (Nouroudine, 2001). No âmbito de um projeto de desenvolvimento da pesca artesanal em Comores, que visava, entre outros objetivos, a favorecer a prática de uma pesca em alto-mar com o fim de preservar as espécies pelágicas costeiras, duas técnicas de pesca foram introduzidas: as embarcações motorizadas e os dispositivos de concentração de peixes (DCP).

A experiência de apropriação dos DCP revelou que essas técnicas, por mais apreciadas que sejam pelos pescadores, não podiam ser introduzidas de forma mecânica no meio técnico e nas atividades de trabalho dos pescadores, pois existe um conjunto constitutivo de normas do que consideram como definidor, para eles, do profissionalismo de um pescador que viria a ser perturbado pelos DCP. Na comunidade socioprofissional dos pescadores comorenses, o perfil do ofício de 'pescador trilhador' (que procura o peixe, o segue e o captura) é valorizado em detrimento do perfil de 'pescador coletor' ('que apenas recolhe o peixe' em torno dos pontos onde eram colocados os DCP). Ora, os DCP induzem o desenvolvimento do perfil do ofício de 'pescador coletor' e a desvalorização, efetivamente, do perfil de 'pescador trilhador'. A nova técnica dos DCP está, então, no centro de um debate (ou mesmo conflito) de normas que não existiria se o trabalho dos pescadores 
fosse de fato 'informal'. Como, efetivamente, um debate sobre normas (ou um conflito em torno de normas) seria possível se não houvesse uma pluralidade de normas que se contrapõem nas relações sociais que se entrelaçam na atividade de pesca?

\section{A transmissão dos saberes na agricultura como 'aprendizagem informal'}

A transmissão dos saberes nas situações concretas de trabalho é uma dessas atividades qualificadas como informais. Quando se toma o caso da transmissão dos saberes na agricultura em Comores, percebe-se que os saberes úteis para se trabalhar eficazmente nessa área são transmitidos em diferentes lugares e instituições de funções polivalentes: a família, as faixas etárias, as praças públicas, as organizações mutualistas de mobilização da força de trabalho etc. (Nouroudine, 2009). Todavia, essas instituições formam uma rede institucional complexa pela qual cada camponês passa desde a juventude. É o que lhe permite, ao longo de sua vida, aprender o ofício. É verdade que um dispositivo desse tipo é complexo, mas os agricultores em questão sabem perfeitamente se situar nessa rede institucional de transmissão do saber. O fato de que a variedade e a polivalência das instituições sociais pelas quais o saber é transmitido dificilmente tornam visível a função de transmissão que estas cumprem não a torna menos real. Há uma racionalidade própria no funcionamento de um sistema de transmissão desse tipo. Mas ela é diferente daquela das instituições modernas especializadas na função de transmissão dos saberes. Sua pertinência só pode ser avaliada em relação à sua correlação com objetivos sociais variados e com um contexto sociotécnico de parâmetros múltiplos.

\section{O pequeno comércio a mbulante como aspecto da 'economia informal'}

Um dos casos que melhor ilustram a economia dita informal é o do pequeno comércio ambulante. Essa atividade econômica é, em geral, praticada por desempregados que têm dificuldade em encontrar um emprego ou por jovens com poucos anos de escolarização. Estes últimos compram produtos de consumo corrente (massa de tomate, fósforos, dentifrício, sabão etc.) para em seguida vendê-los no mercado ou pelas ruas da capital. O vendedor coloca os produtos em um carrinho de mão, o que lhe permite se deslocar com a mercadoria no mercado, no bairro ou na cidade à procura dos clientes, gritando towa urenge ('pague e leve'). Um jovem vendedor do 'comércio informal' testemunha em um jornal local:

Quando cheguei a Moroni4 por volta de 1995 eu estava desempregado, e com o pouco dinheiro de que dispunha comprei uma caixa de garrafas de massa de 
tomate que eu vendia por unidade. Ganhava entre 20 e 25 francos [0,05 euro] por caixa. Conforme as necessidades dos clientes, eu diversificava os produtos (De Dubaï à la Chine, 2007).

Para garantir uma margem satisfatória de lucro, alguns vendedores ambulantes se organizam para efetuar uma compra coletiva dos produtos fora do país. Um dos vendedores do grupo viaja até a Tanzânia, Dubai ou Madagascar para comprar mercadoria em quantidade suficiente para encher um contêiner. "O business que inunda Comores de produtos têxteis e de bugigangas não para de evoluir. Aos poucos, os comerciantes atraídos pelas sereias do 'mais barato' se aventuram até a China, passando pelos balcões asiáticos: Indonésia, Malásia..." (De Dubaï à la Chine, 2007). O pequeno comércio ambulante, que supostamente pertence à chamada economia informal, está, no entanto, longe de ser desprovido de qualquer norma e organização. Com efeito, os produtos vendidos são escolhidos de forma a que escoem rapidamente; o carrinho de mão é adotado para permitir que o vendedor vá até o cliente com a mercadoria; o bordão regular towa urenge visa a chamar permanentemente a atenção dos passantes para o vendedor e para a mercadoria; a reunião dos vendedores para efetuar a compra dos produtos no exterior tem como objetivo aumentar o lucro etc. Além disso, se a 'economia informal' se distingue ou se aproxima da economia mercantil ou da economia não mercantil, do ponto de vista dos objetivos almejados, isso implica que ela não é desprovida de finalidade estruturante.

\section{Como conhecer o trabalho assim apresentado?}

Um projeto de produção de saber sobre o trabalho apresentado dessa forma remete a determinadas exigências epistemológicas que convém elucidar. É necessária uma análise contextualizada ao mesmo tempo das normas e das atividades para se compreender o trabalho em seus diferentes modos. A abordagem adotada em ergonomia para se estudar a atividade no trabalho mercantil e a aproximação desenvolvida pela ergologia para analisar a atividade humana fornecem balizas interessantes nesse sentido. Todavia, devemse identificar as dificuldades ligadas ao modo de existência das normas nas 'atividades informais' para se prever os meios de superá-las.

\section{Analisar as normas inscrevendo-as em um contexto}

De toda a proposição precedente, resulta que o 'trabalho que não é mais o trabalho' é, efetiva e completamente, um trabalho, mas diferente do trabalho mercantil. O 'trabalho informal' é um trabalho precisamente porque é, 
como todo trabalho, constituído por normas, valores e atividades. Apesar disso, a norma do 'trabalho informal' é diferente das normas do trabalho mercantil. Ela é, notadamente, de acesso relativamente difícil. Muitas vezes é preciso buscá-la na fala, e não na escrita. Sua função organizadora só se dá a perceber na trama das atividades sociais. Isso implica acionar uma análise aprofundada das atividades. Mas, como cada norma intrínseca a uma determinada atividade está estreitamente correlacionada às normas de outras atividades, a coerência de uma norma particular só pode ser esboçada em uma abordagem sintética da realidade social própria ao coletivo de vida em questão. Quando este é organizado de maneira tal que a satisfação das necessidades de seus membros pode passar igualmente pelo trabalho mercantil, pelo trabalho não mercantil e pelo 'trabalho informal' (e que essas diferentes formas do trabalho, em vez de se oporem sistematicamente, muitas vezes se completam), surge um fenômeno de circulação das normas, valores, atividades, saberes... de uma forma de trabalho para outra que complexifica o esforço de compreendê-las. É esse o sentido do exemplo retomado por Yves Schwartz no tocante aos três tipos de uso do peixe capturado pelos pescadores em Comores: a parte do peixe que é dada, a que é vendida e a que é destinada ao consumo familiar. ${ }^{5}$ Essa modalidade de uso do peixe pelos pescadores do país condensa em si mesma o trabalho não mercantil (produzir para dar e para o próprio consumo), o trabalho mercantil (produzir para vender) e o 'trabalho informal' (visto que a pesca é considerada como um 'trabalho informal').

\section{O estudo das normas em ergonomia e em ergologia}

Para que a produção de um saber sobre o trabalho seja possível, é preciso dirigir a análise para aquilo que tenha sentido ou significação no trabalho em questão. Por isso era importante começar por mostrar e demonstrar que o 'trabalho informal' não é realmente informal e que não existe um modelo de trabalho do qual as outras formas de trabalho não passariam de pálidas cópias imperfeitas. Disciplinas como a ergonomia da atividade e a ergologia, que analisam respectivamente o trabalho e a atividade humana, constroem suas abordagens metodológicas em torno de hipóteses (que, na verdade, são bem mais do que hipóteses) centradas na norma no âmbito do trabalho e da atividade.

Em ergonomia da atividade, analisar o trabalho é fazer o estudo do trabalho prescrito, do trabalho real, mas sobretudo da distância entre os dois. Compreender o trabalho é, de qualquer forma, dar conta do sentido da atividade como gestão da distância que há entre o prescrito e as condições reais do trabalho. 
Essa prescrição, dizem os autores de Comprendre le travail pour le transformer [Compreender o trabalho para transformá-lo], se impõe ao operador: ela lhe é, portanto, exterior, ela determina e constrange sua atividade. Mas, simultaneamente, ela é um quadro indispensável para que ele possa operar: determinando sua atividade, ela a autoriza (Guérin et al., p. 34-35).

Consequentemente, é importante considerar o prescrito como norma, por um lado, no processo de gestão do distanciamento pelos protagonistas do trabalho e, por outro, na formulação de hipóteses, de forma que o analista do trabalho explique a distância entre o 'prescrito' e o 'real'.

Segundo a ergologia, em qualquer atividade humana há, necessariamente, normas elaboradas anteriormente às atividades. São 'normas antecedentes' que comportam diversas formas de antecipação às quais os protagonistas se referem para realizar as atividades (Schwartz, 2000). Esse conceito engloba os saberes relativamente estabilizados, que são da ordem de um protocolo experimental (o prescrito, os objetivos, as regras, as missões...), e os oriundos da experiência (culturas de ofício, know-how, valores...). No curso da atividade, e para levar em consideração os parâmetros imprevistos da situação de trabalho (variabilidade, randomização, disfunções...), os protagonistas do trabalho procedem a reajustes das normas antecedentes. O processo de construção no qual as normas antecedentes estão correlacionadas às características das situações de trabalho para produzir normas adequadas às condições reais da atividade é chamada 'renormalização'. A norma antecedente e a renormalização, em ergologia, são importantes como referências para realização das atividades e para a análise da distância entre as normas e as condições reais do trabalho.

Em ergonomia da atividade, o princípio epistemológico maior na produção de saber sobre o trabalho é, portanto, a distinção entre o 'prescrito' e o 'real'. Em ergologia, o princípio epistemológico central na produção de saber sobre a atividade humana reside na dialética entre a norma antecedente e a renormalização.

\section{Dificuldades e exigências ligadas ao estudo das normas nas 'atividades informais'}

Partindo-se da importância da análise dos processos de produção das normas no estudo das atividades humanas, a questão de saber o que significa conhecer o trabalho quando o trabalho não é mais o trabalho está estreitamente ligada à seguinte: como ter acesso às normas e às renormalizações do 'trabalho informal' e do trabalho não mercantil? Considerando tudo o que precede (especialmente no que diz respeito à oralidade como veículos 
das normas, à polivalência institucional e à mestiçagem das normas na vida social), o esforço intelectual, orientado para a identificação e o reconhecimento das normas nas atividades, terá que superar pelo menos duas grandes dificuldades.

A primeira diz respeito à compreensão da distância entre o 'prescrito' e o 'real' ou entre a 'norma antecedente' e a 'renormalização'. Para analisar essa distância, é preciso também identificar o prescrito ou a norma antecedente. Ora, essa identificação é difícil de realizar por causa do papel menor do escrito nos processos de produção das normas no 'trabalho informal' e no trabalho não mercantil. É verdade que a escrita apresenta a vantagem de 'fixar' a norma e torná-la visível. Inversamente, quando a fala é o suporte da norma, isso a torna difícil de identificar e conhecer. Além disso, a fala como veículo principal, ou mesmo exclusivo, da norma está exposta mais facilmente aos erros de julgamento e de interpretação a respeito dos processos de renormalização acionados nas atividades humanas.

A segunda dificuldade reside na complexidade das normas quando as dimensões da vida social (o econômico, o social, o religioso, o artístico...) se misturam e se mestiçam, como frequentemente acontece nos países em que o trabalho não mercantil e o 'trabalho informal' são importantes. Também nesse nível os riscos de erro são importantes ao se tentar identificar e compreender as normas pertinentes no que diz respeito a uma atividade particular, isolada, para facilitar a análise, mas estreitamente ligada a outras atividades da realidade social. Se é verdade que as atividades sociais de um coletivo de vida formam um sistema cuja estabilidade relativa é efeito de uma atualização das normas, ao longo da experiência, segundo um processo de renormalização, então a coerência de uma norma social só pode ser compreendida se esta for situada no sistema de normas ao qual pertence. Dito de outra maneira, compreender uma norma social implica dar conta de sua mestiçagem e esboçar o feixe interativo das normas no sistema em foco. Isso supõe observar os coletivos de vida envolvidos para buscar, além dos conservantismos aparentes, as transformações que se realizam nas profundezas da experiência.

Uma leitura positiva dessas dificuldades pode ser feita sistematizandoas em termos de exigências epistemológicas colocadas pelo esforço de produção de saber sobre atividades humanas cuja complexidade o 'trabalho informal' e o trabalho não mercantil permitem, sem dúvida, melhor apreender. Existem, com efeito, duas a três exigências epistemológicas que parecem difíceis de ignorar quando se pretende compreender as atividades humanas: a integração da multidimensionalidade e a consideração da singularidade.

Para integrar a multidimensionalidade das atividades, é preciso adotar uma abordagem pluridisciplinar. A função da pluridisciplinaridade é permitir apreender as múltiplas dimensões (econômicas, jurídicas, sociais...) 
que constituem as atividades e compreender melhor as normas, assim como os processos de renormalização que nelas estão atuando. Como nenhuma das dimensões particulares é suficiente para constituir o trabalho como atividade humana socializada, uma abordagem unidisciplinar só poderá conduzir a uma simplificação artificial ao mesmo tempo das atividades e das normas estudadas. Mas um procedimento pluridisciplinar efetivo e eficaz não pode se resumir a ser apenas a expressão de uma compilação de disciplinas diferentes que se justapõem. Então, uma colaboração interdisciplinar em torno de um projeto de saber claramente formulado parece ser uma condição mínima para que a pluridisciplinaridade possa funcionar.

Para se levar em conta as singularidades das atividades, ou seja, a maneira específica como os saberes e os valores se combinam e se desdobram nas atividades realizadas em um determinado coletivo de vida, é necessário associar os protagonistas do trabalho ao projeto de produção de saber sobre as atividades das quais são autores. Estes últimos detêm saberes investidos na atividade, diferentes dos saberes acadêmicos, mas necessários para se compreender o trabalho. Além disso, se a questão das normas, em suas relações com as atividades, deve ser considerada na complexidade, então três aspectos diferentes, mas complementares, das normas devem merecer atenção: as normas sobre o trabalho (leis e costumes gerais que regem o trabalho), as normas no trabalho (normas antecedentes produzidas nas situações de trabalho) e as normas como trabalho (trabalho de renormalização efetuado ao longo da atividade). Ora, acessar esses diferentes aspectos das normas parece difícil, ou mesmo impossível, sem a colaboração ativa dos protagonistas do trabalho no processo de produção de saber sobre o trabalho dos quais eles são, individual ou coletivamente, os sujeitos.

Mas não é por um efeito mecânico que a dupla colaboração - de um lado, entre as disciplinas e, de outro, com os protagonistas do trabalho - poderá funcionar. Para que as colaborações de geometria variável possam se colocar no âmbito de um dispositivo dinâmico a três polos (DD3P), 6 o primeiro polo (a colaboração entre as disciplinas) e o segundo polo (a colaboração com os protagonistas do trabalho) só podem se constituir e funcionar na presença do terceiro polo, no qual são definidas duas exigências, uma ética e uma epistemológica. A exigência epistemológica postula que toda produção de saber sobre as atividades humanas requer a colaboração de seus autores e que elas sejam abordadas em sua complexidade. A exigência ética veicula uma concepção do sujeito humano em que este aspira a ser produtor de suas próprias normas de vida.

No âmbito de um projeto de conhecimento do trabalho em suas diferentes manifestações históricas, esse DD3P apresenta pelo menos duas virtudes importantes. Primeira, ele neutraliza as manifestações etnocêntricas que levam a qualificar como informal, de imediato, qualquer atividade 
humana que não seja mercantil. Segunda, ele pode favorecer uma produção de saberes sobre as atividades humanas que podem ser investidos nos projetos de desenvolvimento adaptados às realidades locais dos coletivos de vida em questão.

\section{Notas}

1 Professor da Faculté des Sciences et Techniques, Université des Comores, Maroni, Comores. Doutor em Filosofia pela Université de Provence, França. < abdanourodine@ comorestelecom.km>

Correspondência: Département d'Ergologie, Université de Provence, 29, Avenue Robert Schuman, 13621, Aix-en-Provence, Cedex 1, França.

2 A União das Comores, ou mais simplesmente Comores, é uma república federal insular que compreende três das quatro ilhas principais do arquipélago das Comores, entre a costa oriental da África e Madagascar. (N. Revisão Técnica).

3 Alain Morice é autor de várias publicações sobre trabalho informal no Brasil e na África, entre eles: Les Forgerons de Kaolack: travail non salarié et déploiement d'une caste au Senegal, 1982, Paris: EHESS (Tese de doutoramento); Les travailleurs du bâtiment à João Pessoa (Brésil). In: Lautier, B. (Org.), Informalité, formation et emploi: une comparaison entre Colombie et le Nordeste brésilien, Rapport GREITD/CREPPRA-Ministère de l'Education Nationale, 1990. (N. Revisão Técnica).

4 Capital da União das Comores. (N. Revisão Técnica).

5 Desenvolvemos essa ideia em Nouroudine (2001).

6 O dispositivo dinâmico a três polos (DD3P) é o quadro epistemológico a partir do qual a ergologia estuda as atividades humanas. Para aprofundar o tema, ver Schwartz (2000) e Di Ruzza e Halevi (2003).

* Este artigo foi traduzido, do original francês, por Irene Ernest Dias. A revisão técnica foi feita por Daisy Moreira da Cunha. 


\section{Referências}

CANGUILHEM, Georges. Le normal et le pathologique. Paris: Quadrige, PUF, 1991.

DE DUBAÏ À LA CHINE, le 'rêve américain' des petits commerçants. Kashkazi, Moroni (Camores), n. 68, dez. 2007.

DI RUZZA, Renato; HALEVI, Joseph. De l'économie politique à l'ergologie: lettre aux amis. Paris: Harmattan, 2003.

GUÉRIN, François et al. Comprendre le travail pour le transformer: la pratique de l'ergonomie. Lyon: ANACT, 1997.

LAUTIER, Bruno. L'économie informelle dans le tiers monde. Paris: La Découverte, 1994.

MAUSS, Marcel. Sociologie et anthropologie. Paris: Quadrige, PUF, 1997.
NOUROUDINE, Abdallah. Techniques et cultures: comment s'approprie-t-on des technologies transférées?. Toulouse: Octarès Editions, 2001.

Des situations de production de savoirs aux lieux de leur transmission: le cas de la production de vanille aux Comores. In: GESLIN, Philippe (Dir.). Réflexions sur l'anthropotechnologie. Paris: Éditions Octarès, 2009.

SAHLINS, Marshall. Au cœur des sociétés. Paris: Gallimard, 1980.

SCHWARTZ, Yves. Le paradigme ergologique ou un métier de philosophe. Toulouse: Octarès Editions, 2000. 